\title{
INFLUÊNCIA DA COBERTURA VEGETAL DE INVERNO E DA ADUBAÇÃO ORGÂNICA E, OU, MINERAL SOBRE AS PROPRIEDADES FÍSICAS DE UMA TERRA ROXA ESTR UTURADA ${ }^{(\mathbf{1})}$
}

\author{
F. ANDRE OLA ${ }^{(2)}$, L. M. COSTA $^{(3)} \&$ N. OLSZEVSKI ${ }^{(4)}$
}

\begin{abstract}
RESUMO
O presente trabalho objetivou avaliar a influência da cobertura vegetal de inverno, constituída de uma associação de aveia preta (Avena strigosa Schreb) com nabo forrageiro (Raphanus sativus L.), da adubação orgânica com esterco de aves, da adubação orgânica e mineral e da adubação mineral sobre propriedades físicas do solo, numa Terra Roxa Estruturada do estado de Santa Catarina. As análises foram realizadas em amostras de solo coletadas em agosto de 1994 e janeiro de 1995, nas profundidades de 0-10, 10-20 e 20-30 cm, em um experimento iniciado em 1990. Verificou-se uma redução na estabilidade de agregados maiores que $4,76 \mathrm{~mm}$, quando se fez uso de adubação orgânica, bem como aumento na estabilidade de agregados das classes de diâmetro 4,76 a 2,00 e 2,00 a 1,00 mm. Na camada de solo de 0-10 cm, observou-se que o adubo orgânico aumentou a macroporosidade e diminuiu a densidade do solo, enquanto a adubação orgânica e mineral reduziu a macroporosidade e aumentou a microporosidade e a densidade do solo.
\end{abstract}

Termos de indexação: cobertura do solo, adubação verde, sucessão de culturas.

SUMMARY: INFLUENCE OF WINTER WINTER PLANT COVER AND
ORGANIC AND, OR, MINERAL FERTILIZER ON THE
PHYSICAL PROPERTIES OF A STRUCTURED "TERRAROXA"

This study was carried out to assess theinfluence of Winter plant cover on thephysical soil properties in a Structured Terra Roxa soil in the state of Santa Catarina. The plant

\footnotetext{
(1) Parte da Tese de Doutorado do primeiro autor apresentada ao Departamento de Solos da Universidade Federal de Viçosa - UFV. Recebido para publicação em setembro de 1999 e aprovado em junho de 2000.

(2) Pesquisador da Empresa de Pesquisa Agropecuária e Difusão de Tecnologia de Santa Catarina - EPAGRI. Caixa Postal 791, CEP 89801-970 Chapecó (SC).

(3) Professor Titular do Departamento de Solos da Universidade Federal de Viçosa - UFV. Bolsista do CNPq.

(4) Mestranda do Departamento de Solos, UFV. Bolsista da CAPES.
} 
cover consisted of an association of black oats (Avena stirgosa Schreb) with pastureturnip (Raphanus sativus L.) and organic fertilization with poultry manureand ${ }^{2}$ mineral fertilization. Soil samples collected in August 1994 and January 1995, at depths of 0-10, 10-20 and 20-30 cm, from an experiment started in 1990, were analyzed. A decrease in the stability of aggregates greater than $4.76 \mathrm{~mm}$ and an increase in aggregate stability in diameters of 4.76-2.00 and 2.00-1.00 mm was found when organic fertilization was used. Organic fertilizer in the 0-10 cm soil layer increased macroporosity and decreased soil density, whereas the organomineral fertilizer reduced macroporosity and increased microporosity and soil density.

Index terms: green manuring, plant cover, crop rotation.

\section{INTRODUÇÃO}

A região oeste do estado de Santa Catarina caracteriza-se pela predominância de pequenas propriedades rurais. Essas propriedades, assentadas em solos de relevo acidentado e intensamente utilizados, têm provocado conseqüências desastrosas em se tratando de conservação do solo. Com isso, tem ocorrido rápida degradação física equímica dos principais sol os agricultáveis nessas propriedades.

Dentre as causas que contribuem para essa degradação, destacam-se: a pouca cobertura do solo durante o inverno, o preparo muito tempo antes do estabelecimento das culturas, a ocorrência dechuvas de alta intensidade no período em que o solo está desprotegido, a declividade acentuada (entre 8 e $25 \mathrm{~cm} \mathrm{~m}^{-1}$ ) e a baixa reposição de fertilizantes e materiais orgânicos.

Em geral, os solos em seu estado natural, sob vegetação nativa, apresentam características físicas, como permeabilidade, estrutura, densidade do solo eespaço poroso, agronomicamente desejáveis. Nessa situação, o volume de sol o explorável pelas raízes é grande. Entretanto, à medi da que os sol os vão sendo trabalhados motomecanicamente, consideráveis alterações físicas vão ocorrendo.

Tem-se verificado que o tempo de uso dos solos agrícolas, principalmente em sistema de preparo convencional, reduz o teor de matéria orgânica no sol o ocasionado pel o aumento da erosão (Stevenson, 1986) ou pelo revolvimento do solo, que torna um ambiente favorável ao aumento da atividade microbiana e, conseqüentemente, aumento da decomposi ção emineral ização (Costa \& Coel ho, 1990; Andrade \& Colozzi Filho, 1991); reduz o diâmetro médio dos agregados (Costa \& Coel ho, 1990; Fucks et al., 1994) e a estabilidade dos agregados (Costa, 1990; Roth et al., 1990); reduz a macroporosidade e aumenta a microporosidade (Oliveira et al., 1983); reduz a velocidade de infiltração da água (Anjos et al., 1994) e a capacidade de retenção de umi dade do solo (Sidiras et al., 1983); aumenta a densidade do solo (Anjos et al., 1994) e o selamento superficial, com conseqüente aumento do escoamento da água (Alves et al., 1995).
Diversos trabal hos têm mostrado efeito benéfico da cobertura vegetal sobre as propriedades físicas do solo (Nuernberg et al., 1986; Carpenedo \& Mielniczuk, 1990; Costa, 1990). Entretanto, o tipo de manejo dispensado à cobertura pode ou não afetar as propriedades físicas do solo.

Quando a cobertura é utilizada para semeadura direta da cultura subseqüente, al gumas propriedades físicas podem ser alteradas. N ormal mente, verificase que a densidade do solo e a microporosidade aumentam, especial mente na camada de $0-20 \mathrm{~cm}$ de profundidade, sendo isso atribuído ao nãorevolvimento do solo eao tráfego demáquinas (Abrão et al., 1979; Derpsch et al., 1991; Merten \& Mielniczuk, 1991). Apesar disso, a taxa de infiltração é pouco afetada, por causa da formação de canais biológicos criados por animais do solo e por raízes (Derpsch et al., 1991).

Por outro lado, quando a cobertura do solo é incorporada, apesar de muitas vezes ser uma quantidade considerável de massa, parece haver pouca influência sobre as propriedades físicas do solo. I sso porque a prática da aração e da gradagem cria condições favoráveis à decomposição do material incorporado e não há acúmulo de matéria orgânica e, em determinadas situações, especial mentequando a relação $\mathrm{C} / \mathrm{N}$ for muito estreita $(<20: 1)$, pode haver decomposição da matéria orgânica do próprio solo (Broadebent \& Nakashima, 1974). Nesse caso, o efeito da cobertura vegetal produzida para ser incorporada ao sol o é efêmero. Resumindo: quando em estado vegetativo, sua ação sobre as propriedades físicas é indireta, pela proteção física da superfície do solo, evitando a degradação superficial, e direta, pelo crescimento das raízes. Com a incorporação, todo o trabalho realizado pela cobertura é destruído. Assim, algumas propriedades, como a formação e a estabilidade de agregados, a retenção de água, a porosidade e a aeração do solo, são alteradas.

A incorporação de esterco de animais ou outros materiais orgânicos e as práticas de preparo do solo em condições adequadas de umidade podem promover efeitos benéficos nas características físicas do solo, tais como: aumento da microporosidade e retenção de água em solos arenosos (Hafez, 1974; 
Weil \& Kroontje, 1979). O efeito dos dejetos animais sobre a estabilização dos agregados do sol o em água varia desolo para soloe, muitas vezes, são necessárias aplicações durante vários anos para que as diferenças sejam detectadas (Weil \& K roontje, 1979).

Por outrolado, uma redução na densidade do solo e na suscetibilidade à compactação e um aumento no fluxo de água através do solo saturado podem depender do teor de fibras do esterco utilizado (Hafez, 1974). Segundo Epstein (1975) e Weil \& K roontje (1979), a taxa de infiltração de água pode diminuir nos períodos imediatamente após a aplicação de al tas doses de esterco, especial mente o de aves (Epstein, 1975), em razão do diminuto tamanho das partículas, da alta densidadee do baixo teor de fibras desse esterco em relação a outros.

Em solos com pH el evado, altas doses de esterco, principalmente o de aves, aplicadas anualmente sobre a superfície, ou semi-incorporadas, podem provocar prejuízos nas suas características físicas, comoencrostamento, maior facilidade dedesagregação das suas partículas pel o impacto das gotas de chuva, redução na condutividade hidráulica saturada em razão do entupimento dos poros pela dispersão das argilas provocada por íons monovalentes eformação de substâncias cerosas repelentes à água, culminando com uma redução da umidade na capacidade decampo (Hinrichs et al., 1974; E pstein, 1975; E pstein et al., 1976; Weil \& Kroontje, 1979).

Butierres (1980), estudando o efeito do cal cário e da adubação fosfatada sobre o ponto de carga zero (PCZ) e o grau de floculação de sol os do Rio Grande doSul, encontrou resultados que demonstraram que o uso da calagem aumentou o pH correspondente ao PCZ e o fosfato acarretou-Ihe pequena diminuição.

O presente trabal ho teve como objetivo avaliar a influência da cobertura vegetal de inverno e da adubação orgânica e, ou, mineral sobre propriedades físicas do solo, numa Terra Roxa Estruturada do estado de Santa Catarina.

\section{MATE RIAL E MÉTODOS}

As avaliações quími cas reportadas nestetrabal ho foram realizadas em amostras de sol o col etadas em um experimento de sucessão de culturas e de adubação, iniciado em 1990, no município de Chapecó (SC). A área experimental localiza-se na latitude $27^{\circ} 07^{\prime} \mathrm{S}$, longitude $52^{\circ} 37^{\prime} \mathrm{W}$ e altitude de $670 \mathrm{~m}$. O clima regional, deacordo com a classificação de Köppen, é o Cfa (Clima Subtropical Ú mido).

As temperaturas médias mensais são baixas durante o inverno, variando de 11,3 a $16,4^{\circ} \mathrm{C}$ no mês mais frio, e altas durante o verão, variando de 22,6 a $25^{\circ} \mathrm{C}$ no mês mais quente. As chuvas distribuemse normalmente ao longo de todo o ano, sem um período de seca definido. O mês de agosto de 1994 foi excepcional mente seco, com um total de $35 \mathrm{~mm} \mathrm{e}$ o mês de janeiro de 1995 foi bastante chuvoso (261 mm), porém, com precipitação total acima da média, dentro da faixa de precipitações para o mês de janeiro.

O experimento foi instalado em uma Terra Roxa Estruturada distrófica com declividade média de $17 \mathrm{~cm} \mathrm{~m}^{-1}$. Algumas características físicas do sol o da área experimental, analisadas em junho de 1989, antes da implantação do experimento, são apresentadas no quadro 1.

As culturas envolvidas na sucessão foram: feijão (Phaseolus vulgarisL., var. Carioca) emilho (Zea mays L., hib. Pioneer 6875) e, no tratamento com cobertura vegetal deinverno, uma associação denabo forrageiro (Raphanus sativus L.) com aveia preta (Avena strigosa Screb.). Os rendimentos médios de matéria seca da parte aérea da cobertura vegetal de inverno são mostrados no quadro 2.

\section{Quadro 1. Características físicas do solo da área experimental, considerando a profundidade de amostragem}

\begin{tabular}{lccc}
\hline \multirow{2}{*}{ Característica física } & \multicolumn{3}{c}{ Profundidade } \\
\cline { 2 - 4 } & $\mathbf{0 - 1 0}$ & $\mathbf{1 0 - 2 0}$ & $\mathbf{2 0 - 3 0}$ \\
\cline { 2 - 4 } & \multicolumn{3}{c}{$\mathrm{cm}$} \\
\hline Densi dade de partícula $(\mathrm{g} \mathrm{cm}-3)^{(1)}$ & 2,67 & 2,69 & 2,62 \\
Densidade do solo $\left(\mathrm{g} \mathrm{cm}^{-3}\right)^{(2)}$ & 1,14 & 1,37 & 1,25 \\
Areia grossa (\%)(3) & 4,17 & 4,02 & 4,39 \\
Areia fina (\%)(3) & 15,92 & 14,91 & 14,46 \\
Silte (\%)(3) & 25,18 & 26,02 & 25,23 \\
Argila (\%)(3) & 54,73 & 55,05 & 56,92 \\
Macroporos $\left(\mathrm{m}^{3} \mathrm{~m}^{-3}\right)^{(4)}$ & 0,214 & 0,025 & 0,053 \\
Microporos $\left(\mathrm{m}^{3} \mathrm{~m}^{-3}\right)^{(4)}$ & 0,388 & 0,435 & 0,483
\end{tabular}

(1)Método do balão volumétrico. ${ }^{(2)}$ Método do anel volumétrico. ${ }^{(3)}$ Método da pipeta. ${ }^{(4)}$ Método da mesa de tensão, conforme EMBRAPA (1979).

\section{Quadro 2. Rendimento médio anual de matéria seca da parte aérea da cobertura de inverno}

\begin{tabular}{lc}
\hline \multicolumn{1}{c}{ Tratamento } & Rendimento \\
\hline & $\mathrm{kg} \mathrm{ha}^{-1}$ \\
Testemunha (cobertura de & \\
inverno/feijão/milho (a) e vegetação & \\
espontânea/feijão/milho (e)) & 3.987 \\
Adubo orgânico (AO) & 7.565 \\
Adubos orgânico e mineral (AOM) & 6.512 \\
Adubo mineral (AM) & 5.475 \\
\hline
\end{tabular}


Os adubos utilizados anualmente nas culturas de feijão e de milho foram: (a) adubo orgânico (AO) na forma de esterco de aves, constituído do acúmulo de esterco de três lotes de frangos de corte e cama com maravalhas. Algumas características dessetipo de esterco são apresentadas no quadro 3; (b) adubo orgânico e mineral (AOM) na forma de esterco de aves complementado com $\mathrm{N}$ (uréia) e $\mathrm{K}$ (cloreto de potássio); (c) adubo mineral (AM) na forma de uréia $(\mathrm{N})$, superfosfato triplo $(\mathrm{P})$ e cl oreto de potássio $(\mathrm{K})$.

As quantidades de nutrientes utilizadas nas culturas de feijão e de milho seguiram as recomendações da Rede Oficial de Laboratórios de Análise de Solos da Região Sul (REDE..., 1987). As recomendações para o feijoeiro foram de 85(N), $20\left(\mathrm{P}_{2} \mathrm{O}_{5}\right)$ e $40\left(\mathrm{~K}_{2} \mathrm{O}\right) \mathrm{kg} \mathrm{ha}^{-1} \mathrm{e}$, para o milho, considerando um rendimento médio de 3 a $6 \mathrm{t}$ ha-1, foram de $110(\mathrm{~N}), 40\left(\mathrm{P}_{2} \mathrm{O}_{5}\right)$ e $60\left(\mathrm{~K}_{2} \mathrm{O}\right) \mathrm{kg} \mathrm{ha}^{-1}$. Todavia, houve exceção com relação ao AO, cuja quantidade foi cal culada deacordo com a quantidade do nutriente requerido em maior quantidade, no caso o nitrogênio. $O$ fósforo e o potássio foram col ocados em excesso. J á o cálculo da quantidade de esterco de aves para o AOM foi feito de acordo com o nutriente requerido em menor quantidade, para cada uma das culturas. Neste caso, o fósforo.

O quadro 4 mostra as fontes eas quantidades de adubos utilizados anual mente nas culturas de feijão e de milho. Embora a quantidade de nitrogênio requerida pela cultura do milho seja maior que aquela requerida pela cultura de feijão, utiliza-se menos $\mathrm{AO}$, porque se considera que $20 \%$ do $\mathrm{N}$ do adubo aplicado na cultura do feijão permanece no sol o e é utilizado na cultura do milho.

\section{Quadro 3. Características químicas de três lotes do esterco de aves (na matéria seca). Médias de três aviários e três repetições por aviário}

\begin{tabular}{cr}
\hline Elemento & Teor \\
\hline & $\mathrm{g} \mathrm{kg}^{-1}$ \\
$\mathrm{~N}$ & 33,435 \\
$\mathrm{P}$ & 18,850 \\
$\mathrm{~K}$ & 21,750 \\
$\mathrm{Ca}$ & 30,435 \\
$\mathrm{Mg}$ & 5,300 \\
$\mathrm{~S}$ & 2,222 \\
$\mathrm{Cu}$ & 0,056 \\
$\mathrm{Fe}$ & 3,525 \\
$\mathrm{Mn}$ & 0,215 \\
$\mathrm{Zn}$ & 0,355 \\
$\mathrm{Na}$ & 19,490 \\
$\mathrm{CO}$ (carbono orgânico) & 731 \\
\hline
\end{tabular}

Quadro 4. Fontes e doses de adubos utilizados nas culturas de feijão e de milho

\begin{tabular}{|c|c|c|c|}
\hline Cultura & Adubação & Fonte & Dose \\
\hline & & & $\mathrm{kg} \mathrm{ha}^{-1}$ \\
\hline \multirow[t]{7}{*}{ Feijão } & orgânica & esterco de aves & 5.312 \\
\hline & orgânica + mineral & esterco de aves & 952 \\
\hline & & uréia & 155 \\
\hline & & cloreto de potássio & 27 \\
\hline & mineral & uréia & 189 \\
\hline & & superfosfato triplo & 49 \\
\hline & & cloreto de potássio & 67 \\
\hline \multirow[t]{7}{*}{ Milho } & orgânica & esterco de aves & 4.750 \\
\hline & orgânica + mineral & esterco de aves & 1.585 \\
\hline & & uréia & 175 \\
\hline & & cloreto de potássio & 33 \\
\hline & mineral & uréia & 245 \\
\hline & & superfosfato triplo & 98 \\
\hline & & cloreto de potássio & 100 \\
\hline
\end{tabular}

O experimento foi iniciado em 1990 e constou de oi to tratamentos: (a) cobertura de inverno/feijão/ milho; (b) cobertura de inverno + $\mathrm{AO} / \mathrm{feijão;} \mathrm{AO} /$ milho; (c) cobertura de inverno +AOM/feijão; AOM/ milho; (d) cobertura de inverno + AM/feijão; $A M /$ milho; (e) vegetação espontânea/feijão/milho; (f) vegetação espontânea + $\mathrm{AO} / \mathrm{feijão;} \mathrm{AO} / \mathrm{milho}$; (g) vegetação espontânea +AOM/feijão; AOM/milho; (h) vegetação espontânea +AM/feijão; $A M /$ milho. Os tratamentos considerados como testemunhas foram: cobertura de inverno/feijão/milho (a) e vegetação espontânea/feijão/milho (e).

O delineamento experimental foi o de faixas, arranjado em um esquema fatorial $2 \times 4$, sendo 0 primeiro fator constituído pela cobertura (presença eausência) e o segundo constituído pel as adubações, com quatro repetições. As parcel as foram de $6 \times 6 \mathrm{~m}$, com área útil de $4 \times 4 \mathrm{~m}=16 \mathrm{~m}^{2}$. Os resultados obtidos foram submetidos à análise de variância, realizada para cada profundidade, desdobrando-se os graus de liberdade para tratamentos (tipos de adubos e testemunha, nos sistemas com e sem cobertura), mediante os seguintes contrastes ortogonais: $\mathrm{CM}=(-1) \mathrm{S} / \mathrm{C}+(1) \mathrm{C} / \mathrm{C}$ e dentro S/C e dentro de $\mathrm{C} / \mathrm{C}$ e $\mathrm{Cl}=(-3) \mathrm{T}+(1) \mathrm{AO}+(1) A O M+$ (1)AM: $C 2=(-1) A O+(-1) A M+(2) A O M$; $C 3=(-1) A O$ + (1)AM. Esses contrastes foram testados com base no quadrado médio do resíduo das análises de variância. A utilização de contrastes ortogonais como análise estatística é justificada por promover independência de comparação entre tratamentos. 
A cobertura de inverno foi semeada a lanço, nas entrelinhas do milho, ao final do mês de abril. Por ocasião da floração plena da cobertura de inverno, que ocorreu ao final do mês de agosto, foi feito o acamamento com grade de discos. A incorporação, juntamente com o AO e a parte orgânica do AOM, previamente distribuídos nas parcelas, foi realizada com arado de discos. Antes da semeadura do feijão, realizada em meados de setembro, foi feita uma gradagem para a incorporação do AM e partemineral do AOM. Esta prática serviu, também, para complementar o preparo do solo. O mil ho foi semeado no início de janeiro, após a colheita do feijão. Os adubos para a cultura do mil ho foram distribuídos a Ianço nas parcel as e incorporados manualmente com enxada.

Ao final do terceiro ano completo de experimentação (agosto de 1994), foram coletadas as amostras de solo, para a caracterização física do solo, sendo esta col eta realizada em apenas uma trincheira por parcela. Esta amostragem correspondeu à época 1. E mambos os casos, as amostras foram col etadas nas profundidades de 0-10, 10-20 e 20-30 cm.

As determi nações físicas real izadas nas amostras de solo foram: argila dispersa em água, conforme método descrito por J ucksch (1987); equival ente de umidade, densidade do solo, macro e microporos, conforme métodos utilizados pela E MBRAPA (1979), e estabilidade de agregados em água, seguindo método proposto por Kemper \& Chepil (1965).

\section{RESULTADOS E DISCUSSÃO}

\section{Estabilidade de agregados em água}

Observou-seque, nas condições desteexperimento, não houve, em média para as adubações, efeito significativo da cobertura sobre a estabilidade dos agregados (Quadro 5). Todavia, houve tendência de aumento, embora não-significativo, na percentagem dos agregados maiores $(>4,76 \mathrm{~mm}$ ) nas duas primeiras camadas $(0-10$ e $10-20 \mathrm{~cm})$. Tal tendência pode ter sido causada pelo sistema radicular das plantas de cobertura e por parte do sistema radicular do milho que permaneceu no solo por ocasião da col eta das amostras.

Noprocesso deformação dos agregados, as raízes, ao penetrarem no solo, comprimem as partículas, aproximando-as, e, no processo de estabilização dos agregados maiores, além do efeito das raízes que formam um emaranhado no solo, há o efeito das hifas

Quadro 5. Percentagens dos agregados estáveis em água por classe de diâmetro, consi derando cobertura vegetal, adubação, profundidades de amostragem e valores dos contrastes ortogonais. Médias de quatro repetições

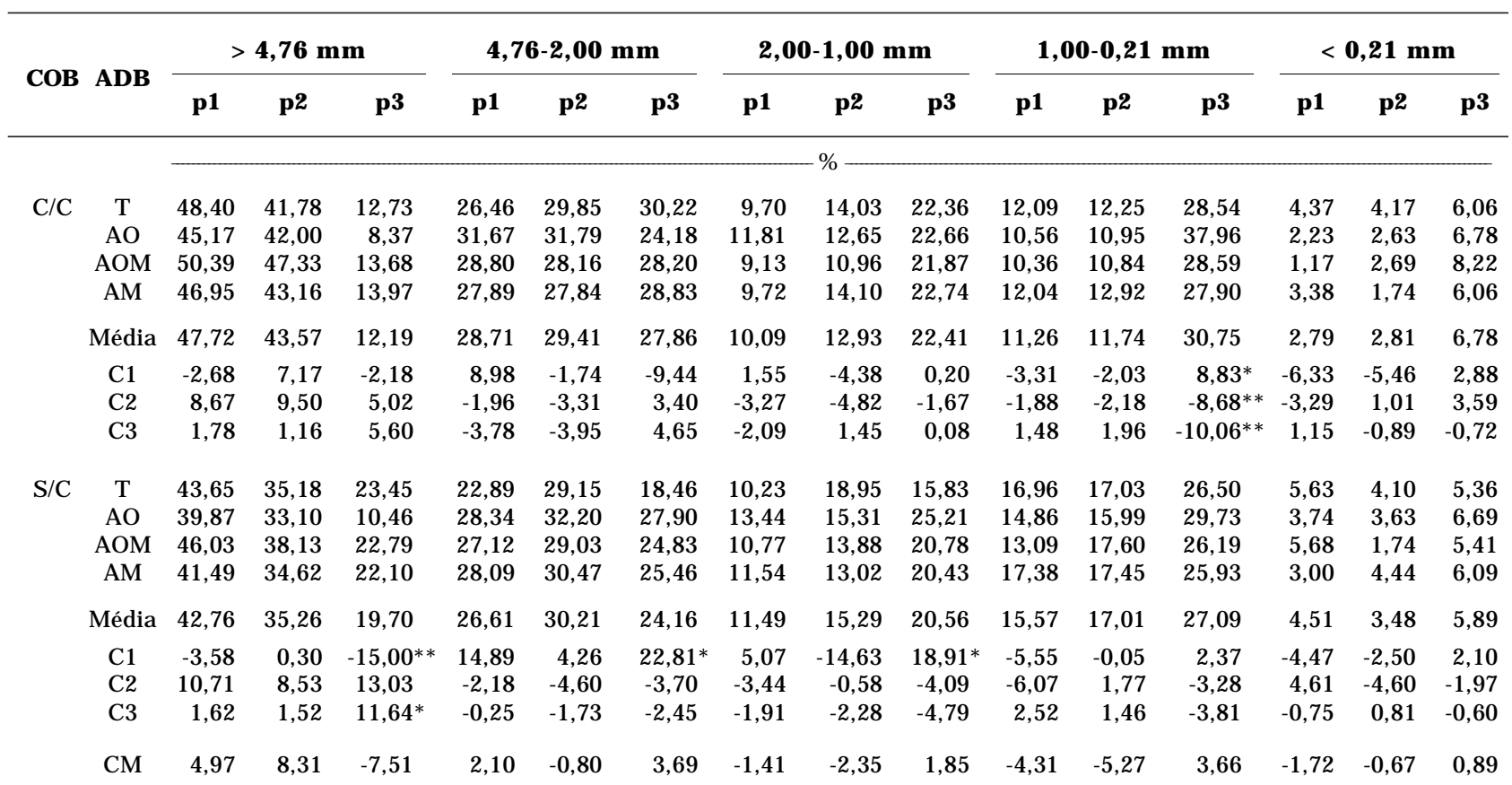

$\mathrm{COB}=$ cobertura; $\mathrm{ADB}=$ adubação; $\mathrm{C} / \mathrm{C}=$ com cobertura; $\mathrm{S} / \mathrm{C}=$ sem cobertura; $T$ =testemunha; $\mathrm{AO}=$ adubo orgânico; $\mathrm{AOM}=$ adubos orgânico e mineral; $A M=$ adubo mineral; $C 1=(-3) T+(1) A O+(1) A O M+(1) A M ; C 2=(-1) A O+(-1) A M+(2) A O M ; C 3=(-1) A O+$ (1)AM; $C M=(-1) S / C+(1) C / C ; p 1=$ profundidade $0-10 \mathrm{~cm} ; \mathrm{p} 2=$ profundidade $10-20 \mathrm{~cm} ; \mathrm{p} 3=$ profundidade $20-30 \mathrm{~cm} ; \quad \circ, *, * *=$ significativos, pelo teste $\mathrm{F}$, a 10,5 e $1 \%$, respectivamente. 
dos fungos que estão associados com as raízes. Segundo Dexter (1991), ciclos de umedecimento e secagem do sol o favorecem a formação dos agregados maiores, enquanto períodos secos estão relacionados a altas densidades radiculares. Portanto, é possível que a tendência de aumento dos agregados maiores que $4,76 \mathrm{~mm}$, observado nas camadas superficiais, tenha sido favorecida pela estiagem ocorrida no mês de agosto de 1994, imediatamente antes da coleta das amostras.

Convém ressaltar que as amostras de solo, analisadas para as características físicas, foram coletadas durante a amostragem referente à primeira época (agosto de 1994), período em que as plantas ainda seencontravam vegetando. É possível que o aumento da percentagem de agregados de maior diâmetro tenha sido causado pela ação das raízes, que, conformeinformaram Baver et al. (1972), Perfect et al. (1990) e Carpenedo \& Mielniczuk (1990), atuam na formação deagregados maiores em detrimento de agregados menores.

O efeito da adubação refletiu-se apenas na profundidade de $20-30 \mathrm{~cm}$. Quando se usou cobertura do solo, houve aumento da percentagem de agregados da classe de diâmetro compreendido entre
1,00 e 0,21 mm, sendo o adubo orgânico o responsável pelo aumento observado. Quando não se usou cobertura, a adubação influiu nas classes de agregados de diâmetro mai or que 1,00 mm. Nota-se que a percentagem dos agregados da classe de diâmetro mai or que 4,76 mm diminuiu com o uso do adubo orgânico, quem contribuiu significativamente para a redução da estabilidade dos agregados dessa classe. Por outro lado, nas classes de diâmetro de 4,76 a 2,00 e 2,00 a 1,00 mm, as adubações aumentaram a percentagem dos agregados. Embora os valores dos contrastes não tenham sido significativos, o adubo orgânico foi o que mais contribuiu para o aumento nessas classes. Todavia, não se observou distinção entre os adubos.

\section{Macro e microporosidade}

A cobertura do solo, em média para as adubações, não influiu significativamente nessas duas variáveis (Quadro 6). Entretanto, na camada de $0-10 \mathrm{~cm}$, tanto os macro como os microporos foram alterados pela adubação orgânica emi neral, quereduziu a percentagem de macroporos e aumentou a de microporos. Houve também efeito significativo do adubo orgânico no aumento da percentagem de macroporos no tratamento sem cobertura, naquela mesma profundidade.

Quadro 6. Valores de macro e microporos do solo, considerando cobertura vegetal, adubação, profundidades de amostragem e valores dos contrastes ortogonais

\begin{tabular}{|c|c|c|c|c|c|c|c|}
\hline \multirow{2}{*}{ СОВ } & \multirow{2}{*}{ ADB } & \multicolumn{3}{|c|}{ Macroporo } & \multicolumn{3}{|c|}{ Microporo } \\
\hline & & p1 & p2 & p3 & p1 & p2 & p3 \\
\hline & & & & 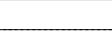 & & & - \\
\hline \multirow[t]{3}{*}{$\mathrm{C} / \mathrm{C}$} & $\begin{array}{c}\mathrm{T} \\
\mathrm{AO} \\
\mathrm{AOM} \\
\mathrm{AM}\end{array}$ & $\begin{array}{l}0,270 \\
0,240 \\
0,204 \\
0,280\end{array}$ & $\begin{array}{l}0,141 \\
0,116 \\
0,127 \\
0,125\end{array}$ & $\begin{array}{l}0,135 \\
0,108 \\
0,125 \\
0,115\end{array}$ & $\begin{array}{l}0,373 \\
0,383 \\
0,406 \\
0,364\end{array}$ & $\begin{array}{l}0,441 \\
0,445 \\
0,441 \\
0,433\end{array}$ & $\begin{array}{l}0,443 \\
0,461 \\
0,449 \\
0,463\end{array}$ \\
\hline & Média & 0,248 & 0,127 & 0,121 & 0,382 & 0,440 & 0,454 \\
\hline & $\begin{array}{l}\text { C1 } \\
\text { C2 } \\
\text { C3 }\end{array}$ & $\begin{array}{l}-0,085 \\
-0,111^{* *} \\
0,040\end{array}$ & $\begin{array}{r}-0,054 \\
0,012 \\
0,009\end{array}$ & $\begin{array}{r}-0,058 \\
0,026 \\
0,006\end{array}$ & $\begin{array}{l}0,033 \\
0,065^{* *} \\
-0,018\end{array}$ & $\begin{array}{r}-0,004 \\
0,004 \\
-0,011\end{array}$ & $\begin{array}{r}0,043 \\
-0,026 \\
0,001\end{array}$ \\
\hline \multirow[t]{4}{*}{$\mathrm{S} / \mathrm{C}$} & $\begin{array}{c}\mathrm{T} \\
\mathrm{AO} \\
\mathrm{AOM} \\
\mathrm{AM}\end{array}$ & $\begin{array}{l}0,262 \\
0,309 \\
0,229 \\
0,251\end{array}$ & $\begin{array}{l}0,125 \\
0,097 \\
0,112 \\
0,165\end{array}$ & $\begin{array}{l}0,126 \\
0,115 \\
0,135 \\
0,129\end{array}$ & $\begin{array}{l}0,360 \\
0,348 \\
0,382 \\
0,380\end{array}$ & $\begin{array}{l}0,450 \\
0,452 \\
0,452 \\
0,416\end{array}$ & $\begin{array}{l}0,461 \\
0,455 \\
0,433 \\
0,443\end{array}$ \\
\hline & Média & 0,263 & 0,125 & 0,126 & 0,368 & 0,443 & 0,448 \\
\hline & $\begin{array}{l}\text { C1 } \\
\text { C2 } \\
\text { C3 }\end{array}$ & $\begin{array}{c}0,001 \\
-0,102^{*} \\
-0,058^{\circ}\end{array}$ & $\begin{array}{r}-0,002 \\
-0,036 \\
0,068\end{array}$ & $\begin{array}{l}0,000 \\
0,026 \\
0,013\end{array}$ & $\begin{array}{l}0,029 \\
0,035^{*} \\
0,032\end{array}$ & $\begin{array}{r}-0,029 \\
0,036 \\
-0,035\end{array}$ & $\begin{array}{l}-0,052 \\
-0,032 \\
-0,012\end{array}$ \\
\hline & CM & $-0,014$ & 0,002 & $-0,005$ & 0,014 & $-0,003$ & 0,006 \\
\hline
\end{tabular}

$\mathrm{COB}=$ cobertura; $\mathrm{ADB}$ = adubação; $\mathrm{C} / \mathrm{C}=$ com cobertura; $\mathrm{S} / \mathrm{C}$ = sem cobertura; $\mathrm{T}$ =testemunha; $\mathrm{AO}=$ adubo orgânico; $\mathrm{AOM}=$ adubo orgânico e mineral; $A M=$ adubo mineral; $C 1=(-3) T+(1) A O+(1) A O M+(1) A M ; C 2=(-1) A O+(-1) A M+(2) A O M ; C 3=(-1) A O+$ (1)AM; $C M=(-1) S / C+(1) C / C ; p 1=$ profundidade $0-10 \mathrm{~cm} ; \mathrm{p} 2=$ profundidade $10-20 \mathrm{~cm} ; \mathrm{p} 3$ = profundidade $20-30 \mathrm{~cm}$.

$\circ, *, * *=$ significativos, pelo teste $\mathrm{F}$, a 10,5 e $1 \%$, respectivamente. 
Com relação às profundidades, observou-se tendência de diminuição de macroporos e aumento de microporos em profundidade. Resultados semelhantes foram encontrados por Oliveira et al. (1983). Esta tendência foi semel hante àquela observada antes do início do experimento (Quadro 1). Observou-se também pouca alteração na percentagem de microporos. Valedestacar oaumento de macroporos em relação ao encontrado antes de se iniciar o experimento. Observou-se, neste caso, que, independentemente do uso de cobertura ou de adubação, houve com o manejo aumento de macroporos no solo, mel horando, assim, a aeração e a infiltração de água no solo.

Outra razão para o aumento de macroporos em relação aos macroporos encontrados no início do experimento pode ser o efeito das raízes da cultura do milho, uma vez que a coleta das amostras foi realizada no inverno e as raízes do milho podem ainda apresentar algum efeito. Conforme Dexter (1991), as raízes, ao penetrarem no solo, comprimem as suas partículas, formando canais (bioporos). Com a morte e decomposição das raízes, os bioporos permanecem e, com isso, os macroporos são aumentados.

\section{Densidade do solo}

Essa característica física também não foi influenciada pela cobertura do solo (Quadro 7). Os adubos, por seu turno, apresentaram efeito significativo (teste $F$ a 10, 5 e1\%) apenas na camada superficial $(0-10 \mathrm{~cm}) .0$ adubo organomineral aumentou, de maneira significativa, a densidade do solo, independentemente da cobertura; enquanto o adubo orgânico reduziu-a no tratamento sem cobertura.

O aumento da densidade do sol o provocada pelo adubo organomineral foi acompanhado da redução de macroporos e do aumento de mi croporos no solo. J á a redução da densidade provocada pelo adubo orgânico foi associada ao aumento de macroporos e à diminuição dos microporos, embora esta não seja significativa.

Independentemente do tipo de tratamento, observou-se aumento da densidade do solo na profundidade de $10-20 \mathrm{~cm}$, indicando certo grau de adensamento do solo nessa profundidade. Este processo pode ser atribuído ao não-revolvimento do solo e ao tráfego de máquinas (Abrão et al., 1979; Derpsch et al., 1991; Merten \& Mielniczuk, 1991; Anjos et al., 1994).

Quadro 7. Valores de densidade do solo, equivalente de umidade e argi la dispersa em água, considerando cobertura vegetal, adubação, profundidades de amostragem e valores dos contrastes ortogonais

\begin{tabular}{|c|c|c|c|c|c|c|c|c|c|c|}
\hline \multirow{2}{*}{ СОВ } & \multirow{2}{*}{ ADB } & \multicolumn{3}{|c|}{ Densidade do solo } & \multicolumn{3}{|c|}{ Equivalente de umidade } & \multicolumn{3}{|c|}{ Argila dispersa em água } \\
\hline & & p1 & p2 & p3 & p1 & p2 & p3 & p1 & p2 & p3 \\
\hline & & 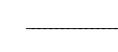 & $-\mathrm{g} \mathrm{cm}^{-3}$ & - & $\longrightarrow$ & $-m^{3} m^{-3}-$ & - & $\longrightarrow$ & - $\%$ & - \\
\hline \multirow[t]{3}{*}{$\mathrm{C} / \mathrm{C}$} & $\begin{array}{c}\mathrm{T} \\
\mathrm{AO} \\
\mathrm{AOM} \\
\mathrm{AM}\end{array}$ & $\begin{array}{l}1,15 \\
1,18 \\
1,21 \\
1,12\end{array}$ & $\begin{array}{l}1,28 \\
1,33 \\
1,31 \\
1,32\end{array}$ & $\begin{array}{l}1,19 \\
1,27 \\
1,27 \\
1,26\end{array}$ & $\begin{array}{l}0,259 \\
0,264 \\
0,258 \\
0,262\end{array}$ & $\begin{array}{l}0,274 \\
0,271 \\
0,271 \\
0,277\end{array}$ & $\begin{array}{l}0,287 \\
0,286 \\
0,286 \\
0,291\end{array}$ & $\begin{array}{l}21,98 \\
22,46 \\
21,75 \\
21,02\end{array}$ & $\begin{array}{l}20,24 \\
21,52 \\
20,02 \\
19,88\end{array}$ & $\begin{array}{l}0,88 \\
1,23 \\
1,88 \\
1,04\end{array}$ \\
\hline & Média & 1,16 & 1,31 & 1,25 & 0,261 & 0,273 & 0,288 & 21,80 & 20,42 & 1,26 \\
\hline & $\begin{array}{l}\text { C1 } \\
\text { C2 } \\
\text { C3 }\end{array}$ & $\begin{array}{c}0,05 \\
0,12^{\circ} \\
-0,06\end{array}$ & $\begin{array}{r}0,12 \\
-0,03 \\
0,00\end{array}$ & $\begin{array}{r}0,23 \\
0,01 \\
-0,01\end{array}$ & $\begin{array}{r}0,007 \\
-0,009 \\
-0,002\end{array}$ & $\begin{array}{r}-0,002 \\
-0,005 \\
0,006\end{array}$ & $\begin{array}{r}0,001 \\
-0,005 \\
0,005\end{array}$ & $\begin{array}{r}-0,71 \\
0,02 \\
-1,44\end{array}$ & $\begin{array}{r}0,69 \\
-1,37 \\
-1,64\end{array}$ & $\begin{array}{r}1,50 \\
1,48 \\
-0,19\end{array}$ \\
\hline \multirow[t]{4}{*}{$\mathrm{S} / \mathrm{C}$} & $\begin{array}{c}\mathrm{T} \\
\mathrm{AO} \\
\mathrm{AOM} \\
\mathrm{AM}\end{array}$ & $\begin{array}{l}1,15 \\
1,06 \\
1,19 \\
1,17\end{array}$ & $\begin{array}{l}1,28 \\
1,33 \\
1,32 \\
1,24\end{array}$ & $\begin{array}{l}1,25 \\
1,25 \\
1,26 \\
1,23\end{array}$ & $\begin{array}{l}0,254 \\
0,255 \\
0,258 \\
0,251\end{array}$ & $\begin{array}{l}0,268 \\
0,268 \\
0,272 \\
0,267\end{array}$ & $\begin{array}{l}0,283 \\
0,281 \\
0,284 \\
0,278\end{array}$ & $\begin{array}{l}20,37 \\
21,36 \\
21,08 \\
20,49\end{array}$ & $\begin{array}{l}19,05 \\
20,58 \\
19,09 \\
18,28\end{array}$ & $\begin{array}{l}1,27 \\
1,25 \\
1,33 \\
1,00\end{array}$ \\
\hline & Média & 1,14 & 1,29 & 1,25 & 0,255 & 0,269 & 0,281 & 20,83 & 19,25 & 1,21 \\
\hline & $\begin{array}{l}\text { C1 } \\
\text { C2 } \\
\text { C3 }\end{array}$ & $\begin{array}{l}-0,02 \\
0,15^{*} \\
0,11^{* *}\end{array}$ & $\begin{array}{r}0,03 \\
0,08 \\
-0,09\end{array}$ & $\begin{array}{r}-0,01 \\
0,04 \\
-0,01\end{array}$ & $\begin{array}{r}0,002 \\
0,010 \\
-0,003\end{array}$ & $\begin{array}{r}0,002 \\
0,008 \\
-0,001\end{array}$ & $\begin{array}{r}-0,005 \\
0,008 \\
-0,003\end{array}$ & $\begin{array}{r}1,82 \\
0,30 \\
-0,87\end{array}$ & $\begin{array}{r}0,79 \\
-0,68 \\
-2,30\end{array}$ & $\begin{array}{r}-0,24 \\
0,42 \\
-0,25\end{array}$ \\
\hline & CM & 0,02 & 0,02 & 0,00 & $0,006^{*}$ & $0,006 *$ & 0,006 & 0,97 & 1,17 & 0,04 \\
\hline
\end{tabular}

$\mathrm{COB}=$ cobertura; $\mathrm{ADB}=$ adubação; $\mathrm{C} / \mathrm{C}=$ com cobertura; $\mathrm{S} / \mathrm{C}=$ sem cobertura; $\mathrm{T}$ =testemunha; $\mathrm{AO}=$ adubo orgânico; $\mathrm{AOM}=$ adubo orgânico e mineral; $A M=$ adubo mineral; $C 1=(-3) T+(1) A O+(1) A O M+(1) A M ; C 2=(-1) A O+(-1) A M+(2) A O M ; C 3=(-1) A O+$ (1)AM; $C M=(-1) S / C+(1) C / C ; p 1=$ profundidade $0-10 \mathrm{~cm} ; \mathrm{p} 2=$ profundidade $10-20 \mathrm{~cm} ; \mathrm{p} 3$ = profundidade $20-30 \mathrm{~cm}$.

$\circ, *, * *=$ significativos, pelo teste $\mathrm{F}$, a 10,5 e $1 \%$, respectivamente. 
O manejo a que a área foi submetida, como uso de cobertura do sol o durante o inverno, uso de adubo orgânico e diminuição das operações de preparo do solo, levou a uma pequena redução da densidade do solo na profundidade de $10-20 \mathrm{~cm}$, passando de $1,37 \mathrm{~g} \mathrm{~cm}^{-3}$, valor observado antes de instalar 0 experimento, para 1,31 notratamento com cobertura e $1,29 \mathrm{~g} \mathrm{~cm}^{-3}$ no tratamento sem cobertura. Nas demais profundidades, praticamente não houve alteração. Nesse contexto, práticas mecânicas e métodos biológicos devem fazer parte de uma estratégia de manejo em que as primeiras sejam reduzidas e as últimas sejam aumentadas.

Para Dexter (1991), os métodos biológicos para melhorar a estrutura do solo, diminuir a densidade de camadas compactadas e dar melhor equilíbrio à relação de poros são promissores, porém é um trabalho de longo prazo, principalmente em solos com altoteor deargila. Corroborando essa afirmativa, principalmente no que se refere à camada compactada, Maltoni (1994) verificou que a camada compactada persistiu após seis anos do plantio da cultura de eucalipto, portanto, após cessado o movimento de máquinas.

\section{Equivalente de umidade}

Apenas a cobertura do solo apresentou efeito significativo sobre essa variável, e o efeito ocorreu nas profundidades de 0-10 e 10-20 cm (Quadro 7). O que se observa está relacionado com o aumento do teor de carbono orgânico naquelas profundidades e está de acor do com observações de Stevenson (1982) de que a matéria orgânica do solo, por meio de seus grupos hidrofílicos, é um dos componentes do solo responsáveis pela retenção de água.

Houve tendência de aumento dos valores de equivalentedeumidade, à medida quea profundidade de amostragem aumenta. Tal fato, possivelmente, ocorreu em virtude da diminuição do teor de areia e do aumento do teor de argila, da menor para a maior profundidade de amostragem. As argilas, por apresentarem alta superfície específica, são as maiores responsáveis pela retenção de água, uma vez que esta é um fenômeno de superfície. Outra provável causa da ocorrência de aumento dos val ores de equivalente de umidade em profundidades é o incremento de microporos.

\section{Argila dispersa em água}

Nem a cobertura nem a adubação apresentaram efeito significativo sobre os valores dessa variável (Quadro 7). Verificou-se diminuição da argila dispersa em água em profundidade, e a maior diferença ocorreu da profundidade de $10-20 \mathrm{~cm}$ para a profundidade de $20-30 \mathrm{~cm}$, em que se verificou maior redução de carbono orgânico no solo, de condutividade elétrica da sol ução do sol o e de maior aumento de $\mathrm{Al}^{3+}$ no solo. Todos esses fatores contribuíram, em maior ou menor grau, para a redução do teor de argila dispersa em água.

\section{CONCLUSÕES}

1. Os adubos apresentaram pouco efeito sobreas características físicas estudadas. A prática da adubação reduziu a estabilidade dos agregados maiores que $4,76 \mathrm{~mm}$, cabendo ao adubo orgânico a maior contribuição, e aumentou a estabilidade dos agregados das classes de diâmetro 4,76 a 2,00 e 2,00 a $1,00 \mathrm{~mm}$.

2. Na camada de $0-10 \mathrm{~cm}$, o adubo orgânico aumentou os macroporos ediminuiu a densidade do solo, enquanto a adubação orgânica e mineral reduziu os macroporos e aumentou os microporos e a densidadedo solo. As demais características físicas não foram alteradas pela prática da adubação.

\section{LITE RATURA CITADA}

ABRÃO,P.U.R.; GOEFERT, C.F.; GUERRA, M.; ELTZ, F.L.F. \& CASSOL, E.A. E feitos de sistemas de preparos do sol o sobre características de um Latossolo Roxo distrófico. R. Bras. Ci. Solo, 3:169-172, 1979.

ALVES, A.G.C.; COGO, N.P. \& LEVIEN, R. Relações da erosão do solo com a persistência da cobertura vegetal morta. R. Bras. Ci. Solo,19:127-132, 1995.

ANDRADE, D.S. \& COLOZZI FILHO, A. Decomposição microbiana de resíduos vegetais em sistemas de plantio convencional e direto. In: REUNIÃO CENTRO-SUL DE ADUBAÇÃO VERDE E ROTAÇÃO DE CULTURAS, 3., Cascavel, 1991. Resumos. Cascavel, OCE PAR, 1991. p.150.

ANJ OS, J .T.; UBERTI, A.A.A.; VIZZOTTO, V.J .; LEITE, G.B. \& KRIEGER, M. Propriedades físicas em sol os sob diferentes sistemas de uso e manejo. R. Bras. Ci. Solo, 18:139-145, 1994.

BAVER, L.D.; GARDNER, W.H. \& GARDNER, W.R. Soil physics. New York, J ohn Wiley \& Sons, 1972. 498p.

BROADEBENT, F.E. \& NAKASHIMA, T. Mineralization of carbon and nitrogen in soil amended with carbon-13 and nitrogen15 labeled plant material. Soil Sci. Soc. Am. Proc., 38:313315, 1974.

BUTIERRES, M.F.M. Efeito do cal cário e fosfato de potássio no ponto de carga zero (PCZ) e grau de floculação em três solos do Rio Grande do Sul. Santa Maria, Universidade Federal de Santa Maria, 1980. 59p. (Tese de Mestrado)

CARPENEDO, V. \& MIELNICZUK, J. Estado de agregação e qualidade de agregados em Latossolo Roxo submetido a diferentes sistemas de manejo. R. Bras. Ci. Solo, 14:99-105, 1990.

COSTA, A.C.S. \& COELHO, S.M.R. E feito do manejo do solo em Latossolo Vermel ho Escuro textura média no município de Paranavaí (PR). II . Estabilidade de agregados em água. In: CONGRESSO BRASILEIRO E ENCONTRO NACIONAL DE PESQUISA SOBRE CONSERVAÇÃO DO SOLO, 8., Londrina, 1990. Resumos. Londrina, Sociedade Brasileira de Ciência do Solo, 1990. p.60. 
COSTA, A.C.S. E feito do manejo do solo em Latossolo Vermel ho Escuro textura média no município de Paranavaí (PR). I. Características físicas. In: CONGRESSO BRASILEIRO E ENCONTRO NACIONAL DE PESQUISA SOBRE CONSERVAÇÃO DO SOLO, 8., Londrina, 1990. Resumos. Londrina, Sociedade Brasileira de Ciência do Solo, 1990. p.59.

DERPSCH, R.; ROTH, C.H.; SIDIRAS, N. \& KÖPKE, U. Controle da erosão no Paraná, Brasil: Sistemas de cobertura do solo, plantio direto e preparo conservacionista do solo. Londrina, IAPAR/GTZ, 1991. 272p.

DEXTER, A.R. Amelioration of soil by natural processes. Soil Till. Res., 20:87-100, 1991.

EMPRESA BRASILEIRA DE PESQUISA AGROPECUÁRIA EMBRAPA. Centro Nacional de Pesquisas de Solos. Manual de métodos de análise do solo. Rio de J aneiro, 1979.212p.

EPSTEIN, E. Effect of sewage sludge on some soil physical properties. J . Environ. Qual., 4:139-142, 1975.

EPSTEIN, E.; TAYLOR, J .M. \& CHANEY, R.L. Effects of sewage sludge and sludge compost applied to soil on some soil physical and chemical properties. J . Environ. Qual., 5:422426, 1976.

FUCKS, L.F.;REINERT, D.J .; CAMPOS, B.C.; BORGES, D.F. \& SCAPINI, C. Degradação da estabilidade estrutural pela aração e gradagem de solo sob plantio direto por quatro anos. In: REUNIÃO BRASILEIRA DE MANEJO E CONSERVAÇÃO DO SOLO E DA ÁGUA, 10., Florianópolis, 1994. Resumos. Florianópolis, Sociedade Brasileira de Ciência do Solo, 1994. p.196-197.

HAFEZ, A.A.R. Comparativechanges in soil - physical properties induced by admixture of manure from various domestic animals. Soil Sci., 118:53-59, 1974.

HINRICHS, D.G.; MAZURAK, A.P. \& SWANSON, N.P. Effect of effluent from beef feedlots on physical and chemical properties of soil. Soil Sci. Soc. Am. Proc., 38:661-663, 1974.

J UCKSCH, I. Calagem e dispersão de argila em amostra de um Latossolo Vermel ho E scuro. Viçosa, Universidade Federal de Viçosa, 1987. 37p. (Tese de Mestrado)

KEMPER, W.D. \& CHEPIL, W.S. Sizedistribution of aggregation. In: BLACK, C.A., ed. Methods of soil analysis. Madison, Americam Society of Agronomy, 1965. p.499-510.
MALTONI, K.L. Efeito da compactação e/ou adensamento em subsuperfície de latossolos sob diferentes usos. Viçosa, Universidade Federal de Viçosa, 1994. 139p. (Tese de Doutorado)

MERTEN, G.H. \& MIELNICZUK, J. Distribuição do sistema radicular e dos nutrientes em Latossolo Roxo sob dois sistemas de preparo de solo. R. Bras. Ci. Solo, 15:369-374, 1991.

NUERNBERG, N.J .; STAMMEL, J .G. \& CABEDA, M.S.V. Efeito da sucessão de culturas e tipos de adubação em caraterísticas físicas de um solo da Encosta Basáltica SulRiograndense. R. Bras. Ci. Solo, 10:185-190, 1986.

OLIVEIRA, M.; CURI, N. \& FREIRE, J .C. Influência do cultivo na agregação de um Podzólico Vermelho-Amarelo textura média/argil losa da região de Lavras (MG). R. Bras. Ci. Solo, 7:317-322, 1983.

PERFECT, E.; KAY, B.D.; Van LOON, W.K.P.; SHEAD, R.W. \& POJ ASOK, T. Rates of changes in soil structural stability under forages and corn. Soil Sci. Soc. Am. J ., 54:179-186, 1990.

REDE OFICIAL DE LABORATÓRIOS DE ANÁLISE DE SOLOS - SUL. Recomendação de adubação e calagem para os estados do Rio Grande do Sul e Santa Catarina. Passo Fundo, Empresa Brasileira dePesquisa Agropecuária, 1987. 100p.

ROTH, C.H.; CASTRO FILHO, C. \& MEDEIROS, G.B. Análise detalhada dos fatores físicos e químicos de agregação em um Latossolo Roxo. In: CONGRESSO BRASILEIRO E ENCONTRO NACIONAL DE PESQUISA SOBRE CONSERVAÇÃO DO SOLO, 8., Londrina, 1990. Resumos. Londrina, Sociedade Brasileira de Ciência do Solo, 1990. p.58.

SIDIRAS, N.; DERPSCH, R. \& MONDARDO, A. Influência de diferentes sistemas de preparo do solo na variação da umidade e rendimento da soja em L atossol o Roxo Distrófico (Oxisol). R. Bras. Ci. Solo, 7:103-106, 1983.

STEVENSON, F.J . Humus chemistry. New York, J ohn Wiley \& Sons, 1982. 443p.

STEVENSON, F.J . Cycles of soil-carbon, nitrogen, phosphorus, sulfur, micronutrients. New York, J ohn Weley \& Sons, 1986. 380p.

WEIL, R.R. \& KROONTJ E, W. Physical condition of a Davidson clay loam after five years of heavy poultry manure applications. J . Environ. Qual., 8:387-392, 1979. 
F. ANDREOLA et al. 